\title{
MUITO RUÍDO E POUCAS VOZES: OS DISCURSOS \\ NA RIO+20 E A GOVERNANÇA GLOBAL PARA O DESENVOLVIMENTO SUSTENTÁVEL ${ }^{1}$
}

\author{
Roberto Guimarães* \\ Yuna Fontoura** \\ "Até que ponto nós, como indivíduos, preferimos \\ morrer em vez de nos adaptarmos e sobreviver?"
}

(DIAMOND, 2006, p. 517).

O propósito deste ensaio é realizar uma reflexão crítica, informada por uma abordagem de discurso que mais se aproxima da Genealogia de Michel Focault, uma vez que, a partir da busca

\footnotetext{
${ }^{1}$ Versão resumida e atualizada de artigo submetido pelos autores para publicação no número especial de Cadernos EBAPE, Volume X, número 3, setembro de 2012.

* Doutor em ciência política; Professor e Coordenador do MBA em Gestão do Ambiente e Sustentabilidade da Fundação Getulio Vargas e Professor visitante do Doutorado em Ambiente e Sociedade da Universidade Estadual de Campinas; Fellow do Wissenschaftskolleg, Instituto de Estudos Avançados de Berlim; Pesquisador Principal da Dimensão Socio-Ecológica da Rede sobre Desigualdades na América Latina; Ex-Chefe de Análise Social e Política da ONU; Coordenador Técnico nas Conferências das Nações Unidas sobre Meio Ambiente e Desenvolvimento (Rio-92, Rio+5 e Rio+10). E-mail: robertoguimaraes@hotmail.com.

** Doutoranda em Administração pela Escola Brasileira de Administração Pública e de Empresas da Fundação Getulio Vargas (EBAPE/FGV), mestre em Administração Pública, bacharel em Administração. E-mail: yuna.fontoura@fgv.br.
} 
pelas descontinuidades, das singularidades dos eventos e dos contornos sutis (sem uma finalidade monótona), este método permite um diagnóstico centrado nas relações de poder, na "biopolítica" e na discussão sobre a governança e governabilidade (Foucault, 1972, 2000, 2009; Burrel, 1998; Motta e Alcadipani, 2004). Desta forma, ao analisar os principais discursos que pautaram a Rio+20, buscou-se aprofundar nas relações de poder existentes e, por sua vez, nos principais atores envolvidos. Entretanto, o ensaio não se atém às especificações da Genealogia foucaultiana propriamente dita, uma vez que não se pretende ter por foco a análise precípua de poder.

Dada a corrente dificuldade em lidar com a natureza do ensaio em diferentes campos disciplinares, é importante destacar a priori que "na producão de um ensaio, não ocorre o "aprisionamento formal do ensaì̀sta com o objeto empírico", permitindo assim "refletir em todas as direcões" e "aventurar-se na compreensão do objeto por associacões ou analogias, sem, contudo, render-se ao formalismo da técnica científica tradicional" (Meneghetti, 2011, p. 327). Meneghetti (2011) destaca ainda que

No ensaio, o empírico já está apreendido pela consciência do ensaísta, e este reflete criticamente sobre o objeto. [...] O caráter do objeto refletido pelo ensaísta está associado à capacidade de estabelecer relações diversificadas entre o ensaísta, o objeto apreendido e outros objetos que possam relacionar-se aos dois primeiros (Meneghetti, 2011, p. 326).

Desta forma "no ensaio, não é preciso uma conclusão no sentido tradicional; cada parte é uma conclusão por si mesma. No desenvolvimento do ensaio, são geradas as próprias conclusões para as reflexões anunciadas inicialmente em forma de questionamentos" (Meneghetti, 2011, p. 330).

Esclarecidas as principais especificidades de um ensaio teórico iniciamos a reflexão sobre os discursos que sobressaíram 
durante a Conferência das Nações Unidas sobre Desenvolvimento Sustentável, a Rio+20. Ressalta-se, todavia, que estes discursos não foram apenas enfatizados durante o evento oficial, mas também nos eventos paralelos à cúpula, bem como pelos meios de comunicação, ressaltando a magnitude que tais discursos ganharam durante o evento, transpassando as fronteiras entre ciência, sociedade e governo. São eles: o discurso da segurança alimentar; o da insuficiência do Produto Interno Bruto (PIB) para medir a sustentabilidade do desenvolvimento; o da a credibilidade científica; a economia verde; e, por fim, da importância do setor privado para o desenvolvimento sustentável. Embora sem que um consenso tenha sido alcançado, estes discursos foram amplamente debatidos, sendo defendidos ou até mesmo rejeitados.

Vinte anos após a Rio-92, principal marco global em prol do desenvolvimento sustentável, a Rio+20 tinha como objetivo central a renovação do compromisso político com o desenvolvimento sustentável firmados anteriormente nas principais cúpulas sobre o tema, a fim de avaliar o progresso, identificar lacunas na implementação das decisões adotadas, além do estabelecimento de emergentes (UNCSD, 2012a). Em um contexto de recessão econômica global e mediante a constatação de que pouco se avançou no que tange ao desenvolvimento sustentável nas últimas décadas (Guimarães e Fontoura, 2010; UNEP, 2012) com uma contra-tendência em querer resolvê-lo, a conferência iniciou no dia 13 de junho de 2012 com elevado descrédito por parte da sociedade civil, dos meios de comunicação e da comunidade científica (Antunes e Angelo, 2012; Carvalho, 2012; FOEI, 2012; GREENPEACE, 2012a, 2012b, 2012c; Nogueira, 2012; Pires, 2012a, 2012b; WWF, 2012; Veja, 2012). Além da participação dos chefes e representantes de Estado (mais de 190 países mandaram representantes para o Rio), estiverem presentes nos eventos paralelos: sociedade civil global (composta principalmente por Organizações Não Governamentais - ONGs, cooperativas, comunidades indígenas, comunidades quilombolas, grupos religiosos e demais movimentos sociais); cientistas de 
$\mid 34$ |

Muito ruído e poucas vozes: os discursos...

diferentes áreas; think tanks, comunidades epistêmicas, políticos e representantes do setor privado.

Como um dos discursos mais acentuados na Rio+20, a segurança alimentar foi amplamente debatida sob o argumento central da instabilidade no sistema alimentar, em especial no que se refere à governança alimentar (fortalecimento dos mecanismos de governança e principais atores envolvidos). A segurança alimentar objetiva todo o processo em que o alimento é produzido, processado, distribuído, vendido e consumido. Neste caso, a segurança alimentar estaria ameaçada quando este sistema estivesse sob tensão (Gregory, Ingram e BRKLACICH, 2005).

O atual estado de segurança alimentar global e nutrição é decididamente alarmante. Contraditoriamente, embora a produção mundial de alimentos se mantenha acima da demanda global por muitos anos, cerca de um bilhão de pessoas não possuem acesso à quantidade mínima de calorias diárias. Além disso, enquanto um bilhão de pessoas sofrem deficiência mineral e vitamínica, um bilhão de pessoas sofre de excesso de peso e obesidade. As doenças transmitidas pela alimentação, advindas da ingestão de alimentos contaminados com microrganismos ou produtos químicos, também constituem a pauta da segurança alimentar (FAO, 2012). Publicado em 2011, o relatório da FAO “The state of food insecurity in the world" evidenciou que a crise financeira de 2008 agravou a (in)segurança alimentar, aumentando o preço dos alimentos e, por sua vez, o número de pessoas desnutridas (FAO, 2011). Estima-se que em 2050 a população mundial seja de 9 bilhões de pessoas, o que requer um aumento de $70 \%$ da produção de alimentos (Bullock et al., 2012). Soma-se a isto, segundo estudos na $\mathrm{FAO}$, que o impacto da mudança climática na segurança alimentar tende a ser maior em um futuro próximo (FAO, 2009).

O governo brasileiro liderou este tema durante as negociações na Rio+20. Após muito debate, foi acatada a decisão do Canadá e da Austrália de retirarem a menção à "soberania alimentar", substituindo para "intensificação da produção sustentável de alimentos", não agradando os representantes da sociedade civil, dos países africanos e de Indonésia, com 
populações dependentes da produção agrícola e com elevado índice de pobreza (Pires, 2012b; GREENPEACE, 2012d). Por fim, o documento final não apresentou propostas concretas e efetivas para a segurança alimentar, reconhecendo apenas a sua importância e a necessidade de se repensar um sistema que tenha fundamento a agricultura sustentável, que garanta a qualidade do ecossistema marinho, o direito universal à alimentação, da importância da gestão de riscos de forma a evitar a alta volatilidade dos preços dos alimentos, da adoção de estratégias que sejam internacionais, regionais e locais, do importante papel da FAO, e por fim, reafirmam a necessidade de se estabelecer um sistema de comércio multilateral mais equitativo, não discriminatório com regras bem definidas que vise promover a agricultura em países em desenvolvimento (UNCSD, 2012b).

Logo, a ausência de propostas reais e objetivas em favor da segurança alimentar reafirma os interesses do agronegócio, modelo este responsável pela atual crise alimentar com base no mercado, pelo desestímulo à produção familiar de alimentos e aumento da dependência da importação, e que, ao longo dos anos, também reduz a mão de obra do campo gerando êxodo rural, aumentando a concentração de terras e a utilização de agrotóxicos, contribuindo ainda para a privatização das sementes e produção de alimentos transgênicos.

No caso do Brasil, a produção de commodities gera impactos como o desmatamento, a contaminação por produtos agroquímicos e a perda de fertilidade do solo. Contudo, esta continua sendo a opção política do Estado e incentiva os latifundiários e as empresas transnacionais (ETNs) produtoras de semente que ditam as regras, não apenas no Brasil, mas ao redor do mundo. Já o modelo de soberania alimentar, proposto pelos principais eventos da sociedade civil global, a Cúpula dos Povos e os Diálogos sobre a Sustentabilidade Global, foi descartado pelos representantes dos governos. Neste caso, verifica-se o fracasso do Brasil nas negociações, apesar de ser o segundo maior produtor de transgênicos do mundo, um país 
$|36|$

Muito ruído e poucas vozes: os discursos...

agroexportador e megabiodiverso ao mesmo tempo, favorecendo cada vez mais a "insegurança" alimentar.

Outro discurso com grande repercussão durante a Rio+20 foi a necessidade de um índice que substituísse o PIB como principal indicador de riqueza e desenvolvimento dos países. Para os críticos do PIB, a principal deficiência do índice é que ele mede o fluxo da riqueza que é monetizado pelas transações no mercado, mas não inclui os custos sociais e ambientais envolvidos na produção dessa riqueza. A percepção de que o PIB não responde mais à complexidade atual é crescente não apenas no meio científico e de economistas, mas também entre sociedade civil global, governantes e representantes de organismos internacionais, como ressalta o secretário-geral da ONU, Ban Ki-moon: "Precisamos de um novo paradigma econômico que reconheça a paridade entre os três pilares do desenvolvimento sustentável: bem-estar social, econômico e ambiental. Os três definem a felicidade global bruta" (Vialli, 2012).

Durante a Rio+20, a ONU em conjunto com o International Human Dimensions Programme on Global Environmental Change (IHDP) (think tank ligado à United Nations University) divulgou no Relatório de Riqueza Inclusiva 2012 o Índice de Riqueza Inclusiva (IRI), como indicador alternativo ao PIB. O IRI evidencia aos governos a real situação da riqueza de seus países e a sustentabilidade de seu crescimento. $\mathrm{O}$ relatório demonstrou as alterações na riqueza inclusiva em 20 países tendo como resultado significativas alterações quando comparado ao PIB. Por exemplo, quando o desempenho do Brasil e da China no período são medidos pelo IRI, suas economias crescem, respectivamente, $18 \%$ e $45 \%$, ao invés de $31 \%$ e $422 \%$ (PNUMA, 2012).

Este discurso de substituição ao PIB foi liderado pelo Reino Unido (estabeleceu uma Comissão para o Capital Natural junto ao governo) e pela França (apoiou a já conhecida Comissão Stiglitz - Commission on the Measurement of Economic Performance and Social Progress) e com apoio do governo japonês (PIRES, 2012a). Entretanto, a única menção a este discurso no Futuro que Queremos limitou-se a uma frase na qual os governos apenas 
reconhecem a necessidade de medidas mais amplas de progresso que "complementem" o PIB e solicitam à Comissão Estatística das Nações Unidas, junto às demais entidades do sistema ONU e outras organizações, que estabeleçam um programa voltado para esta questão (UNCSD, 2012b). Em resumo, em nenhum momento o documento menciona o IRI como possível índice, não propõe nenhum índice substituto, e muito menos se aprofunda em analisar o por quê de o PIB estar ultrapassado e as consequências de sua permanência como principal indicador de riqueza e desenvolvimento. Este fato demonstra mais uma vez o quão esvaziado ficou o documento final da conferência.

A "credibilidade científica" também foi um discurso de destaque durante a Rio+20. Embora seja reconhecido que a comunidade científica não compartilha de uma única opinião a respeito dos temas abordados na cúpula (por exemplo, para alguns cientistas a introdução dos transgênicos na agricultura é uma solução para a segurança alimentar, para outros ela representa uma ameaça), sua "credibilidade" emergiu como "legitimador" das futuras ações que a humanidade deva tomar rumo ao desenvolvimento sustentável. Ou seja, este discurso reforça a supremacia da ciência por meio de duas questões centrais: a) a "verdade/solução" para o desenvolvimento sustentável está na ciência; b) se a solução da ciência é esta, então devemos acatá-la. Todavia, após anos de debate em torno do papel da ciência, é notório e compartilhado pelos autores deste ensaio que não existe neutralidade científica e um modelo generalizável para todas as realidades sociais. Como Francis M. Cornford, professor de Literatura Clássica em Cambridge, indicou em seu afiadíssimo e espirituoso Microscomograhpia Acadêmica: Being a Guide for the Young Academic Politician em 1908:

Você pensa (não é mesmo?) que basta formular uma argumentação razoável, e as pessoas devem ouvir a razão e obedecer imediatamente. É justamente esta convicção que o faz tão desagradável. Há pouca esperança em dissuadi-lo; 
|38|

Muito ruído e poucas vozes: os discursos...

mas já lhe ocorreu que nada jamais é feito até que todos estejam convencidos de que deve ser feito, e estão convencidos há tanto tempo que já terá sido hora de se fazer outra coisa? (CORNFORD, 1908:3).

Tal "credibilidade científica" foi apontada nos meios de comunicação (Angelo, Rodrigues e Menchen, 2012; Pires, 2012a; Souza, 2012; Watts, 2012; Wilson, 2012), nos eventos paralelos à cúpula (CÚPULA DOS POVOS, 2012a; RSF, 2012a, 2012b) e reforçada no evento oficial (UNCSD, 2012b). Durante o Fórum de Ciência, Tecnologia e Inovação para o Desenvolvimento Sustentável, em torno de 500 cientistas de 75 países debateram como a relação sociedade-ciência-formadores de políticas públicas pode solucionar a atual crise ambiental, financeira, social, geopolítica e tecnológica por meio de maiores mecanismos de cooperação científica internacional. O evento Diálogos para o Desenvolvimento Sustentável também reforçou este discurso, argumentando que as mudanças ambientais globais requerem de capacidade científica para desenvolver um observatório global do clima que possibilite informações confiáveis para subsidiar a tomada de decisão. Reforçaram ainda o consenso de que o aquecimento global já é confirmado por meio de evidências científicas. O evento oficial, por sua vez, declarou no documento final $O$ Futuro que Queremos consideráveis referências à ciência, tais como: a) a necessidade de fortalecer a interface entre ciência e política pública; b) o desenvolvimento dos Objetivos do Desenvolvimento Sustentável (ODS); c) o estabelecimento de um Fórum Político de Alto Nível, que fortaleça ainda mais a relação ciência-sociedade para o desenvolvimento sustentável (RSF, 2012c).

Com maior visibilidade durante a Rio +20 , a economia verde como ferramenta e instrumento para desenvolvimento sustentável e erradicação da pobreza foi o discurso que mais se propagou durante a conferência, passando a ter destaque de tema central de discussão entre os atores envolvidos. Esta repercussão fez com que temas como energia, florestas, biodiversidade e saúde humana 
ficassem relegados ao segundo plano nos principais eventos durante a cúpula, resultando, inclusive, em uma redução de escopo de análise em torno destes, bem como negligenciando necessidades reais na agenda de desenvolvimento sustentável.

Segundo o relatório final da Rio+20, a economia verde "deveria contribuir para a erradicação da pobreza bem como para o crescimento econômico sustentado, fortalecendo a inclusão social, melhorando o bem estar humano e criando oportunidades de emprego e trabalho decente para todos, mantendo ao mesmo tempo o funcionamento saudável dos ecossistemas da Terra" (UNCSD, 2012b, p. 9). Foi sugerido, portanto, que a economia verde alia o desenvolvimento econômico e a melhoria ambiental, com aumento de renda, emprego e melhoria dos padrões de vida, com o uso sustentável do meio ambiente por meio do mecanismo de preço dos mercados.

Liderado pela União Europeia, e fortemente apoiado pela comunidade científica e pelo setor privado, o discurso da economia verde passou a ser considerado pelos seus defensores como uma potencial solução para os desafios do desenvolvimento sustentável, aumentando, inclusive, a oferta de emprego em 500 milhões, e evitando potenciais riscos para o comércio internacional (Pires, 2012a). Segundo o comissário europeu para o meio ambiente, o economista esloveno Janez Potocnik:

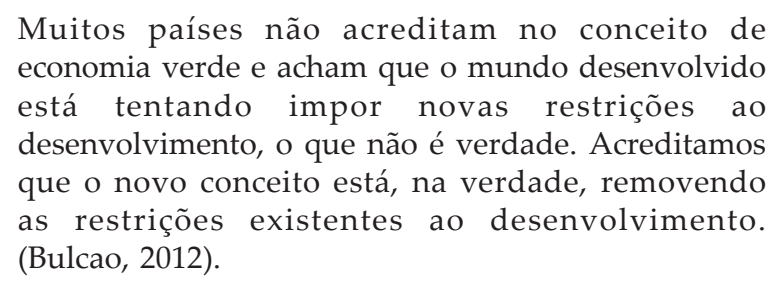

Para os governos que subscreveram este discurso, a economia verde torna possível redirecionar investimento público, estabelecer uma agenda de reforma política para fomentar novos incentivos, eliminar progressivamente produtos menos ecológicos do campo, tornar os contratos públicos mais ecológicos 
$|40|$

Muito ruído e poucas vozes: os discursos..

e fortalecer a infraestrutura de mercado. Já para o setor privado, este modelo econômico seria uma oportunidade de transição econômica em uma série de setores-chave de forma a atender à reforma política por meio de financiamento e investimento.

Entretanto, durante a Rio+20, muitas posições se revelaram antagônicas em relação à economia verde, com fortes divergências entre países desenvolvidos e o bloco G-77+China, incluindo o Brasil, o que também contribuiu para a difusão deste discurso durante a cúpula. Contrária a este discurso, a Cúpula dos Povos, maior evento da sociedade civil global paralelo à Rio+20 (estimase que aproximadamente 40.000 participantes participaram deste evento), destacou em sua declaração final que:

A atual fase financeira do capitalismo se expressa
através da chamada economia verde e de velhos e
novos mecanismos, tais como o aprofundamento do
endividamento público-privado, o superestímulo
ao consumo, a apropriacão e concentracão das
novas tecnologias, os mercados de carbono e
biodiversidade, a grilagem e estrangeirizacão de
terras e as parcerias público-privadas, entre outros.
(CÚPULA DOS POVOS, 2012a).

De acordo ainda com Kumi Naidoo, diretor-executivo do Greenpeace Internacional:

A economia verde foi descrita como uma agenda política que quer preparar o território para a acumulação de capital por meio do controle da natureza, que vai agravar os problemas já existentes no campo, como a grilagem, despejos da população original e concentração de terras (CÚPULA DOS POVOS, 2012b).

Ao final da negociação, o documento $O$ Futuro que Queremos descreveu este discurso de forma pouco ambiciosa para os que, como a União Europeia, o defenderam (UNCSD, 2012b), 
contribuindo mais uma vez para um documento vago, sem propostas objetivas e nada ambicioso.

Partindo de uma perspectiva teórica marxista, Misoczky e Bohm (2012) ressaltam a economia verde como um

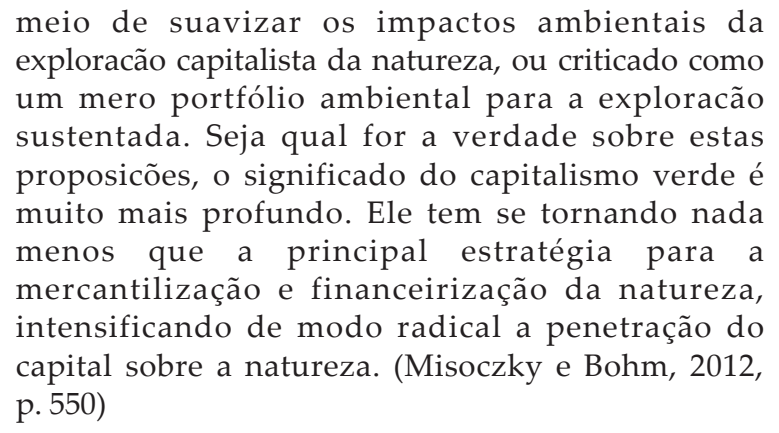

A ambiguidade e as contradições em torno do conceito de economia verde se expressa na busca pelo crescimento econômico à qualquer custo, ao mesmo tempo em que se propõe uma mudança readical, ecológica. Assim como destacado por Misoczky e Bohm (2012, p. 551), durante a Rio+20 pregavam "por um lado, a convocacão para uma virada ecológica e, por outro, a subscrição da necessidade de crescimento econômico, livre-comércio, privatização e desregulamentação".

Além de compartilhar da crítica marxista da economia verde defendida Misoczky e Bohm (2012), este ensaio sustenta também que outros fatores contribuíram para o fracasso desse discurso, talvez "o grande discurso" da Rio+20. Primeiramente, o texto final premaneceu vago, com princípios gerais, sem que uma ação objetiva fosse estabelecida, reconhecendo apenas a necessidade de implantação de uma economia voltada para a sustentabilidade. Em segundo lugar, o tema está longe de ser consensual uma vez que os países em desenvolvimento temem que este se estabeleça como mais uma "receita desenvolvimentista" imposta, regulada e controlada pelo "norte rico" como outras "receitas" desenvolvimentistas do passado, além de proporcionar novas 
medidas protecionistas e subsídios para os países altamente dependentes de seus recursos naturais. Em terceiro lugar, cada país ficou totalmente "livre" para determinar sua "definição" de economia verde. O risco de tornar a economia verde uma proposta ambígua e desprovida de conteúdo está no fato de que, o que $a$ priori parece dar uma certa percepção de "liberdade" sobre as ações a serem tomadas, possibilita aos países simplesmente não fazerem nada, visto que o que é "verde" para um, não necessariamente o é para outro. Em quarto lugar, independente de ser "verde" ou não, a lógica econômica é guiada pelos mercados e pela volatilidade e especulação de preços, o que, pela via do capitalismo neoliberal, já comprovou não ser "sustentável" no sentido amplo, para todos os povos, não apenas para os poucos que dele se beneficiam.

Neste sentido, a economia de mercado e seus atores centrais já demonstraram aos governos e às sociedades no final do ano de 2008 que esta lógica pode acarretar graves consequências, em especial para os mais pobres e com menor poder econômico e político. Parece, portanto, improvável, ilusório, principalmente desde uma perspectiva do "sul", mais especificamente do Brasil (país agroexportador e megadiverso), que a economia verde descentralize o controle da natureza por parte das grandes corporações privadas, bem como solucione os atuais problemas no campo (concentração de terra, grilagem e outros) e garanta a segurança alimentar. Além disso, o discurso da economia verde favorece apenas os interesses do setor privado como agente privilegiado do desenvolvimento sustentável. Tais questões nos levam à seguinte pergunta: seria "green economy" (em português, economia verde) ou "greed economy" (em português, economia gananciosa)?

A presente análise dos principais discursos da Rio+20 revela para os autores deste ensaio que a importância do setor privado para o desenvolvimento sustentável serviu como prédica subjacente às demais. Em outras palavras, trata-se de um discurso de mercado que emerge a partir da união dos demais como intérprete fundamental para o desenvolvimento sustentável, não apenas no documento oficial final da Rio+20, mas também 
mediante eventos paralelos à cúpula, como o Fórum de Sustentabilidade Corporativa, o Fórum de Sustentabilidade Empresarial da Rio+20, a Conferência Internacional do Instituto Ethos, os Eventos Especiais sobre Cidades Sustentáveis e o Seminário Sebrae +20 , entre outros. Identifica-se no documento final a menção ao setor privado mais de vinte vezes ao longo do texto, como agentes que devem se engajar para que o desenvolvimento sustentável seja adotado "todos" os seus principais temas (exemplo, saúde humana, segurança alimentar, mudança climática, biodiversidade, florestas). Some-se a isto o foco dado ao comércio reforçado no documento oficial (UNCSD, 2012b, p. 49, ênfase dos autores):

\begin{abstract}
Reafirmamos que o comércio internacional é um motor para o desenvolvimento e o crescimento sustentado, e reafirmamos também o papel crítico que um sistema multilateral de comércio, universal, baseado em regras, aberto, não discriminatório e equitativo, bem como a liberalização do comércio, pode jogar no estímulo o crescimento econômico e o desenvolvimento em todo o mundo, beneficiando deste modo a todos os países em todos os estágios de desenvolvimento, à medida em que avancem em direção do desenvolvimento sustentável.
\end{abstract}

Verifica-se neste trecho a reafirmação dos valores neoliberais pelos governantes e pela ONU, muito embora esta lógica econômica tenha se mostrado insuficiente para solucionar as crises atuais como destacado anteriormente e que tendem a se agravar, a saber, as crises ambiental, econômica e social. Tais valores, juntamente com o discurso da economia verde, favorecem apenas às grandes corporações privadas dos países desenvolvidos, uma vez que estas serão as grandes beneficiadas pelo modelo de "financiamento" da natureza para o interesse de seus negócios com o rótulo "verde", além de não terem obrigação concreta de alterar seus atuais padrões de produção, gestão, distribuição e contribuição social. No que tange aos combustíveis fósseis, 
$|44|$

Muito ruído e poucas vozes: os discursos...

nenhum compromisso de eliminar os subsídios a esses combustíveis foi apontado no documento final. Não existe, neste caso, consenso entre os governos para que o atual modelo energético seja modificado, favorecendo mais uma vez as empresas de petróleo (produção, refinamento e distribuição) e às grandes montadoras de automóveis. Hart (2005, p. 3) ressaltava que "as corporações são as únicas entidades no mundo contemporâneo com a tecnologia, os recursos, a capacidade e alcance global" suficiente para a resolução dos problemas sociais e ambientais".

A Confederacão Nacional da Indústria(CNI) lançou durante a Rio+20 o "TEEB para o Setor de Negoìcios Brasileiro", iniciativa da Conservacão Internacional (CI-Brasil) com apoio do Centro de Monitoramento da Conservação Mundial (UNEPWCMC) e patrocínio da Monsanto, Natura, Vale e Santander. $\mathrm{O}$ relatório tinha por objetivo dimensionar oportunidades de negócios sustentáveis no que tange ao valor econômico da biodiversidade no Brasil. Destaque para os setores da agricultura, papel e celulose; mineração e construção civil; óleo e gás e químicos; instituições financeiras; cosméticos e farmacêuticos; e varejo (CONSERVAÇÃO INTERNACIONAL, 2012). Durante lançamento do relatório, o então diretor-executivo da CI-Brasil ressaltou:

Os serviços prestados pelos diferentes ecossistemas do planeta têm um grande valor econômico; eles podem valer até trilhões de dólares. Nas últimas décadas, se formos computar o que foi gasto em termos de recursos naturais e de biodiversidade brasileiros, o PIB do país só cresceu 3\%. (CONSERVAÇÃO INTERNACIONAL, 2012).

Durante a cúpula, vinte instituições financeiras lançaram a Declaracão do Capital Natural, demonstrando assim seu "comprometimento" com o chamado Capital Natural:

Atualmente muitas instituições financeiras não compreendem suficientemente, não consideram e, 


\begin{abstract}
portanto, não avaliam os riscos e as oportunidades relacionados ao Capital Natural nos seus produtos e serviços financeiros (empréstimos, investimentos e seguros) e na sua cadeia de suprimentos. A construção deste conhecimento, bem como o desenvolvimento de ferramentas adequadas de valoração e gestão de riscos, para que seja considerado o Capital Natural nos processos de tomada de decisão financeira, são os primeiros importantes passos a serem tomados pelo setor financeiro. (DECLARAÇÃO DO CAPITAL NATURAL, 2012).
\end{abstract}

Isto evidencia que, mais uma vez, estamos diante do "reformismo verde" que aceita as regras do capitalismo, cujas soluções são compatíveis com os interesses da rentabilidade, da competitividade no Mercado, do lucro rápido e do crescimento econômico ilimitado (Misoczky e Bohm, 2012).

Quanto à biossegurança (tema amplamente debatido na Rio-92), a situação atual também não foi alterada, uma vez que no documento $\mathrm{O}$ Futuro que Queremos a menção à inserção dos Organismos Geneticamente Modificados (OGM) no campo não sofreu nenhuma crítica ou ressalva dos possíveis riscos ao meio ambiente, à saúde humana e aos impactos sociais do advento da biotecnologia no campo. O texto apenas reconhece e compreende a necessidade de se promover (sem muita explicação, em dois pontos sem grande destaque) uma agricultura mais inclusiva e que não discrimine as pequenas comunidades agrícolas. Verificase, desta forma, que mais uma vez que o discurso a favor do setor privado prevaleceu na Rio+20, uma vez que as grandes empresas produtoras de semente (como Monsanto, Bayer Cropscience, Syngenta e Dupont) em nada foram afetadas com o evento, estando cada vez mais livres para expandir seus negócios mundo a fora.

A importância do setor privado também é apontada na importância da Responsabilidade Social Corporativa (RSC) para o desenvolvimento sustentável: "Conclamamos o setor privado 
$|46|$

Muito ruído e poucas vozes: os discursos...

a engajar-se em práticas empresariais sustentáveis, como aquelas promovidas pelo Global Compact das Nações Unidas" (UNCSD, 2012b, p. 7). Verifica-se também a valorização da relação entre RSC, governos e melhores práticas de gestão sustentável, retomando a legitimação das práticas dos negócios pelas grandes corporações privadas e a crença no capitalismo de mercado em promover a paz social e a estabilidade (FORT e SCHIPANI, 2004), também destacado no Futuro que Queremos (UNCSD, 2012b, p. 7):

Nós reconhecemos a importância da informação sobre sustentabilidade corporativa e encorajamos as empresas, quando apropriado, em especial as grandes empresas, a considerar a integração da informação sustentável no seu ciclo de informação e de produção de relatórios. Nós encorajamos a indústria, os governos interessados e os atores relevantes, com o apoio do sistema das Nações Unidas, quando apropriado, a desenvolver modelos para melhores práticas e a facilitar a ação para integrar relatórios de sustentabilidade, tomando em conta as experiências de marcos já existentes e colocando atenção particular nas necessidades dos países em desenvolvimento, incluindo a construção de capacidades.

É forçoso reconhecer, lamentavelmente, que tanto o discurso sobre a importância do setor privado como o discurso da economia verde apenas reiteram o poderio das grandes organizações privadas do "norte" e seus interesses de negócio, as quais já demonstraram ter o lucro como principal estratégia inibidora do desenvolvimento sustentável ao longo das últimas décadas.

A análise de discursos efetuada neste ensaio reforça a percepção acerca das relações de poder que se consolidaram durante a Rio +20 , consagradas nos principais resultados advindos da cúpula. Embora o evento tenha sido idealizado como o grande 
evento da década no que se refere ao desenvolvimento sustentável, verifica-se que os líderes mundiais não se voltaram para o caráter de urgência que o tema requer, sem que resultados concretos, com metas, prazos e mecanismos de acompanhamento tenham sido firmados no documento final. Pelo contrário, deixou-se o Rio de Janeiro apenas com decisões vagas e reforçando discursos pouco consistentes e até contraditórios com o paradigma do desenvolvimento sustentável consagrado na Rio-92. Neste caso, sobressaíram a reafirmação dos valores econômicos com base nas propostas neoliberais como principal resultado da Rio+20, ressaltando o poder do setor privado e dos interesses das grandes corporações transnacionais e dos países desenvolvidos na atual agenda de governança ambiental global. As consequências de manter o mesmo modelo econômico com base nos mercados e nas grandes corporações e suas práticas é que pouco ou, de fato, nenhum avanço seja feito para a materialização do desenvolvimento sustentável nas próximas décadas, com consequências negativas para as gerações atuais e futuras.

É digno de registro apenas a sugestão de estabelecimento dos Objetivos do Desenvolvimento Sustentável (ODS), propostos pela Colômbia e Guatemala, como o único resultado positivo da Rio+20, ainda que a sua formulação ainda requeira de ações futuras. Com o objetivo de expandir os Objetivos do Desenvolvimento do Milênio (ODM) que irão até 2015, cabe aos ODS estabelecer indicadores que auxiliem aos governos a implementar compromissos firmados na Agenda 21, no Plano Johanesburgo de Implementação e na Rio+20. Ainda assim, muito foi discutido e pouco foi definido. Deixou-se mais uma vez temas de grande importância para uma discussão futura, e permanece ainda um sentimento generalizado de repetição do fracasso retórico da Rio+10 em Johannesburgo.

Ademais, ressalta-se a incapacidade do governo brasileiro, de quem se esperava ousadia e liderança coerentes com a sua trajetória em temas ambientais desde a Conferência de Estocolmo, no papel privilegiado de anfitrião da Conferência, em liderar as 
$|48|$

Muito ruído e poucas vozes: os discursos...

negociações, pautado com um perfil tão baixo que beirou à burocrática omissão. Assim como ressaltado por Viola e Franchini (2012):

a nova administração federal comandada por Dilma Rousseff é provavelmente a menos sensível às questões ambientais em duas décadas. Como vimos, o modelo de desenvolvimento privilegiado pelo poder executivo - e com altos níveis de aceitação na sociedade e empresariado local - é dominado absolutamente pelo pilar do crescimento econômico. (Viola e Franchini, 2012, p. 509).

Se a sobriedade exige reconhecer que o tempo está realmente se esgotando após o fracasso da Rio+20, a ética da sustentabilidade impõe lembrar que as gerações futuras não nos perdoarão se agirmos como a orquestra do Titanic nos momentos finais antes do naufrágio. Já não é o momento de debater a ciência, a governança, as instituições ou os atores necessários para promover as mudanças necessárias: é tempo de agir. Por mais que ainda exista muito por conhecer, o mundo já está cansado de saber quais desafios são tidos como os mais urgentes, os responsáveis e as formas para superá-los. Assim como destacado por Jared Diamond (2006) em um dos trabalhos mais aclamados na atualidade, ganhador, entre muitos outros reconhecimentos internacionais, do Prêmio Pulitzer: "Até que ponto nós, como indivíduos, preferimos morrer em vez de nos adaptarmos e sobreviver?" (Diamond, 2006, p. 517).

A julgar pelos discursos e resultados da Rio+20, os líderes atuais responderam ao questionamento de Diamond como os protagonistas da obra magistral de William Shakespeare, "A Tempestade" (1610), com muito barulho por nada. Infelizmente, o "barulho" da retórica inconsequente representa uma grave ameaça e coloca em risco a sobrevivência da civilização e das sociedades atuais. 


\section{Bibliografia:}

ANGELO, C.; RODRIGUES, F; MENCHEN, D. Cúpula repete promessas e adia ações para 2015. Folha de São Paulo. Disponível em: <http://www1.folha.uol.com.br/ambiente/ 1109292-cupula-repete-promessas-e-adia-acoes-para2015.shtml>. Acesso em: 25 jun. 2012.

ANTUNES, C.; ANGELO, C. Texto da Rio+20 será 'equilíbrio de descontentamentos', diz negociador. Folha de São Paulo. Disponível em: <http://www1.folha.uol.com.br/ambiente/ 1106400 - texto-da-rio 20 - se ra-equilibrio-dedescontentamentos-diz-negociador.shtml>. Acesso em: 18 jun. 2012.

BULCÃO, L. UE deve lutar contra a crise sem abandonar responsabilidades, afirma comissário europeu. VEJA. Disponível em: <http://veja.abril.com.br/noticia/ internacional/ue-deve-lutar-contra-a-crise-sem-abandonarresponsabilidades-afirma-comissario-europeu>. Acesso em: 17 jun. 2012.

BULLOCK, J. et al. Restoration of ecosystem services and biodiversity: conûicts and opportunities. Disponível em: <http://www2.uah.es/josemrey/Reprints / Bullock_RestorationReview_TREE_2011_online.pdf $>$. Acesso em: 12 jul. 2012.

BURRELL, G. Ciência Normal, Paradigmas, Metáforas, Discursos e Genealogia da análise. In: CLEGG, S. R. (Org.). Handbook de estudos organizacionais. São Paulo: Atlas, v. 1, 1998.

CARVALHO, E. Falta de acordo seria fracasso do sistema internacional, diz ONU. G1. Disponível em: $<$ http://g1.globo.com/natureza/rio20/noticia/2012/06/falta-deacordo-seria-fracasso-do-sistema-internacional-dizonu.html>. Acesso em: 20 jun. 2012. 
CONSERVAÇÃO INTERNACIONAL. TEEB para o setor de negócios brasileiro é lançado na Rio+20: Iniciativa visa a dimensionar o valor econômico da biodiversidade para o setor de negócios no Brasil e identificar oportunidades associadas ao seu uso sustentável. 15 jun. 2012. Disponível em: $<$ http://www.conservation.org.br/noticias/ noticia.php?id=608>. Acesso em: 24 jul. 2012.

CORNFORD, F. M. Microscomograhpia Academica: Being a Guide for the Young Academic Politician. Cambridge: Bowes \& Bowes, 1908 .

CÚPULA DOS POVOS. Rio+20: Documento final foi aprovado. Só três países expressaram reservas. Disponível em: $<$ http://cupuladospovos.org.br/2012/06/rio20-documentofinal-foi-aprovado-so-tres-paises-expressaram-reservas/>. Acesso em: 25 jun. 2012a.

Plenária de Soberania Alimentar debate os motivos da crise alimentar e as soluções camponesas. Disponível em: $<$ http://cupuladospovos.org.br/2012/06/plenaria-desoberania-alimentar-debate-os-motivos-da-crise-alimentar-eas-solucoes-camponesas/>. Acesso em: 21 jun. 2012b.

DECLARAÇÃO DO CAPITAL NATURAL. Declaração do Capital Natural. Disponível em: <http://www.natural capitaldeclaration.org/wp-content/uploads/2012/04/ natural_capital_declaration_port.pdf $>$. Acesso em: 2 ago. 2012.

DIAMOND, J. Colapso: Como as Sociedades Escolhem o Fracasso ou o Sucesso. Rio de Janeiro: Editora Record, 2006.

Food and Agriculture Organization (FAO). The State of Food Insecurity in the World. Rome: UN Food and Agriculture Organisation, 2009.

Summary Report of the Food Security Dialogue Day Organized by FAO, IFAD, WFP and Bioversity International. Disponível em: 
< h t t p: / / w w w.fao.org/rioplus $20 / 33881$ 0ec3e5243e297d17e8f179d9219ab4ec3.pdf>. Acesso em: 16 jul. 2012.

Friends of the Earth International (FOEI). Send a letter to reclaim the UN from corporate capture. Disponível em: $<$ http://www.foei.org/en/get-involved/take-action/reclaimthe-un-from-corporate-capture>. Acesso em: 16 jun. 2012.

FORT, T.; SCHIPANI, C. The Role of Business in Fostering Peaceful Societies. New York: Cambridge University Press, 2004.

FOUCAULT, M. A arqueologia do saber. Lisboa; Porto: Vozes, 1972.

. Estruturalismo e Pós-estruturalismo. In: Ditos \& Escritos, v. II: Arqueologia das Ciências e História dos Sistemas de Pensamento. Rio de Janeiro: Forense Universitária, 2000.

. A origem do discurso: aula inaugural no Collège de France, pronunciada em 2 de dezembro de 1970. São Paulo: Edições Loyola, 2009.

GREENPEACE. Rio+20: High Seas protection possible; right to food? US says:"delete". Disponível em: $<$ http://www.greenpeace.org/international/en/news/Blogs/ makingwaves/rio20-high-seas-protection-possible-right-to/blog/40828/>. Acesso em: 10 jun. 2012a.

. Greenwash+20: How some powerful corporations are standing in the way of sustainable development. Disponível em: <http://www.greenpeace.org/international/ en/publications/Campaign-reports/Climate-Reports/ GreenwashPlus20/>. Acesso em: 15 jun. 2012b.

Rio+20: The Future We Want versus the Powerpoint they negotiate. Disponível em: <http://www.greenpeace.org/ international/en/news/Blogs/makingwaves/rio20-the-futurewe-want-versus-the-powerpoin/blog/40658/>. Acesso em: 15 jun. 2012c. 
- Um fracasso de proporções épicas. Disponível em: $<$ http://www.greenpeace.org/brasil/pt/Noticias/Um-fracassode-proporcoes-epicas/>. Acesso em: 23 jun. 2012d.

GREGORY, P.; INGRAM, J.; BRKLACICH, M. Climate change and food security. Philosophical Transactions of the Royal Society, n. 360, p. 2139-2148, 2005.

GUIMARÃES, R.; FONTOURA, Y. A Natureza Ético-Política das Dimensões Humanas das Mudanças Ambientais Globais. Revista da ANPEGE, v. 6, p. 73-87, 2010.

HART, S. L. Capitalism at the crossroads: the unlimited business opportunities in solving the world's most difficult problems. New Jersey: Wharton School, 2005.

MENEGHETTI, F. K. O que é um ensaio-teórico? Revista de Administração Contemporânea, v. 15, n. 2, p. 320-332, 2011.

MISOCZKY, M. C.; BOHM, S. Do desenvolvimento sustentaìvel aÌ economia verde: a constante e acelerada investida do capital sobre a natureza. Cadernos EBAPE.BR, v. X, n. 3, p. 565-568, 2012.

MOTTA, F. C. P.; ALCADIPANI, R. O pensamento de Michel Foucault na teoria das organizações. Rausp, v. 39, n. 2, p. 117-128, 2004.

NOGUEIRA, I. Cúpula dos Povos rejeita negociação de governos. Folha de São Paulo. Disponível em: $<$ http://www1.folha.uol.com.br/ambiente/1105554-cupulados-povos-rejeita-negociacao-de-governos.shtml>. Acesso em: 18 jun. 2012.

PIRES, M. Cientistas se reúnem para dar sugestões à Rio+20. VEJA. Disponível em: <http://veja.abril.com.br/noticia/ ciencia/comunidade-cientifica-se-reune-para-dar-sugestoes-ario-20>. Acesso em: 14 jun. 2012a.

- Cientistas querem agricultores e ambientalistas trabalhando juntos. VEJA. Disponível em: 
$<$ http://veja.abril.com.br/noticia/ciencia/cientistas-queremagricultores-e-ambientalistas-trabalhando-juntos $>$. Acesso em: 14 jun. 2012b.

Programa das Nações Unidas para o Desenvolvimento (PNUMA). Um novo balanço para as Nações: UNU-IHDP e PNUMA lançam um índice de sustentabilidade que vai além do PIB. Disponível em: <http://www.pnuma.org.br/ comunicados_detalhar.php?id_comunicados $=213>$. Acesso em: 19 jun. 2012.

Rio Science Forum (RSF). Biodiversity: Nature as a Giant Library. Disponível em: $<$ http://rioscienceforum.wordpress.com/2012/ 06/15/biodiversity-nature-as-a-giant-library/>. Acesso em: 20 jun. 2012a.

. A new contract between science and society: Rio Science Forum Day 1. Disponível em: <http://rioscienceforum.wordpress.com/ 2012/06/12/a-new-contract-between-science-and-society-rioscience-forum-day-1/>. Acesso em: 13 jun. 2012b.

Green Economy and Rethinking Social and Economic Models. Disponível em: <http://www.icsu.org/rio20/science-andtechnology-forum/programme/forum\%20recommendations/ GreenEcononyandRethinkingSocialandEconomicModels.pdf $>$. Acesso em: 10 de jul. 2012c.

SOUZA, M. 'Rascunho Zero da Rio+20 deveria ser Rascunho -5', diz Greenpeace. G1. Disponível em: <http://g1.globo.com/ amazonas/noticia/2012/03/rascunho-zero-da-rio20-deveriaser-rascunho-5-diz-greenpeace.html $>$. Acesso em: 24 abr. 2012.

United Nations Conference on Sustainable Development (UNCSD). Sobre a Rio+20. Disponível em: $<$ http://www.rio20.gov.br/sobre_a_rio_mais_20>. Acesso em: 10 jul. 2012a.

The Future We Want. Disponível em: <http://www.uncsd2012.org/content/documents/ 
727The \%20Future\%20We\%20Want\%2019\%20June \% 201230pm.pdf >. Acesso em: 15 jul. 2012b.

United Nations Environmental Programme (UNEP). Global Environment Outlook (GEO-5): summary for policy makers. United Nations Environmental Programme. UNEP: Nairobi, 2012.

VEJA. Para UE, falta ambição ao Brasil em texto da Rio+20. VEJA. Disponível em: $<$ http://veja.abril.com.br/noticia/internacional/ para-ue-falta-ambicao-ao-brasil-em-texto-da-rio-20>. Acesso em: 21 jun. 2012.

VIALLI, A. Especialistas afirmam que medição do PIB é "rústica e omissa". Folha de São Paulo. Disponível em: $<$ http://www1.folha.uol.com.br/ambiente/1101675especialistas-afirmam-que-medicao-do-pib-e-rustica-eomissa.shtml>. Acesso em: 21 jun. 2012.

VIOLA, E.; FRANCHINI, M. Os limiares planetaìrios, a Rio+20 e o papel do Brasil. Cadernos EBAPE.BR, v. X, n. 3, p. 470-491, 2012.

WATTS, J. Rio+20 Earth summit: scientists call for action on population. The Guardian. Disponível em: <http://www.guardian.co.uk/environment/2012/jun/14/rioearth-summit-population-consumption?newsfeed=true $>$. Acesso em: 20 jun. 2012.

WILSON, S. Science is key to our sustainable future. Aljazeera. Disponível em: <http://www.aljazeera.com/indepth/opinion/ 2012/06/20126211211472368.html>. Acesso em: 15 jun. 2012.

World Wildlife Fund (WWF). Rio+20 tem que garantir que o futuro seja sustentável e justo. Disponível em: <http://www.wwf.org.br/ informacoes/noticias_meio_ambiente_e_natureza/?31584>. Acesso em: 13 jun. 2012a. 